\title{
ESTIMATION OF VELOCITY DEPTH MODEL FOR STRUCTURAL TARGETS - A CASE HISTORY FROM THE NORTH SEA
}

\author{
OZ YILMAZ, PAUL FARMER, ANDY PIEPRZAK and BOB GODFREY \\ Schlumberger/Geco-Prakla, Schlumberger House, Buckingham Gate, Gatwick Airport,
}

West Sussex RH6 ONZ, UK

Three-dimensional seismic data from the North Sea were analyzed to remove the deleterious effect of the Zechstein diapiric formation on imaging the underlying Permian sands of Rotliegendes. This Required accurrate imaging of the overburden and delineating the geometry of the halite and anhydride-dolomite units in the Zechstein formation.

By using a field data case from the North Sea, we demonstrate an efficient strategy to conduct inversion project for estimating velocity-depth models for 3-D structural targets. First, a set of utilities built around a workstation is needed to represent, visualize and edit 3-D velocity-depth models. Second, application such as 3-D prestack travel time inversion, and 3-D poststack and prestack depth migration are needed to estimate the velocity-depth models parameters. The latter two application involve numerically-intensive computations and large input-output operations, and therefore, are best implemented on a powerstation, such as massively parallel processors. Finally, one needs to be able to efficiently download and archive largescale data volumes using a serverstation.

The data analysis comprised two stages--conventional processing and velocity-depth models estimation. The subsurface geological models was treated in two parts--the overburden above the salt diapir where time migration often is appropriate and the substratum below the salt diapir where depth migration is imperative. Velocity-depth model building included layer-bylayer application of 3-D prestack travel time inversion to estimate the layer velocity and 3-D poststack depth migration to estimate the reflector geometries. The 3-D time horizons corresponding to Geologically-consistent layer boundaries were interpreted from the DMO stacked volume of data and were used in prestack travel time inversion. Once the overburden model was established, then the velocity-depth model associated with the substratum was estimated by iterative 3-D poststack depth migration, first, followed by 3-D prestack depth migration along selected traverses. The latter was used to generate image gathers which were used to assess inaccuracies in the model.

Layer boundaries included in the analysis are: Base Tertiary, Base Liassic, Base Upper Triassic, Top Bunter, Top Zechstein, Top Rotliegendes, and Carboniferous. The iterations for 3-D poststack depth migration were done using a band of frequencies up to $50 \mathrm{~Hz}$. A final 3-D poststack depth migration then was done to a depth of $5 \mathrm{~km}$.

Results of 3-D poststack depth migration and prestack travel time inversion were combined using an inversion workstation which enabled representation, visualization and editing of the 3-D velocity-depth models from each iteration. The final velocity-depth model accommodated lateral and vertical velocity gradients that are judged to significant within each layer. 